Lung cancer

\section{Lung cancer in never-smokers}

\section{Chee-Keong Toh, Wan-Teck Lim}

\section{The mystery behind never-smokers being more prone to lung cancer is unlocked with regard to smoking status and sex}

$\mathrm{N}$ ever-smokers with lung cancer constitute an understudied and under-represented subset of patients. Although there have been hints that never-smokers can be afflicted with lung cancer, ${ }^{\prime}$ especially among Asian Chinese women, ${ }^{2}$ it is only recently that attention has turned towards this much ignored group of patients. Sparking the attention was the finding that somatic mutations of the epidermal growth factor receptor (EGFR) were consistently more common among lung tumours of neversmokers, ${ }^{3}$ and that these mutations could possibly explain the higher response rates to single agent gefitinib. ${ }^{4}$ The attention was further intensified by media reports of a non-smoking wife of a celebrity who developed lung cancer.

Most studies on never-smokers with lung cancer have emerged from Asia, as the smoking prevalence rates in Asia are lower compared with the West. In Singapore, where the population is predominantly Chinese, the smoking prevalence in the general population is $24.3 \%$ in men and $3.6 \%$ in women. ${ }^{6}$ About $10-$ $15 \%$ of lung cancers occur in a lifetime among never-smokers in the West, ${ }^{7}$ whereas about $30-40 \%$ of patients with lung cancer are never-smokers among the Asian countries. ${ }^{8}$ Whether this represents a higher risk of lung cancer among neversmokers in Asia or is a mere reflection of the higher numbers of never-smokers at risk is unclear at present. A recent large prospective study by Thun et al ${ }^{9}$ may help to put things in perspective. The study among African Americans and Whites provides estimates of mortality due to lung cancer among never-smokers, with rates of 17.1 and 14.7 per 100000 personyears among men and women, respectively. These figures highlight that the burden of lung cancer among neversmokers is fairly significant among the western population. In fact, they are comparable to the death rates due to lung cancer among Chinese women in Singapore, ${ }^{10}$ where only $3.6 \%$ of women smoke in the general population. ${ }^{6}$ Confounding these studies assessing mortality due to lung cancer is the fact that the death rates could be affected by incorrect documentation of cause of death, duration of survival and treatment, and a lack of a uniform definition of current, former and never-smokers. A Japanese study found that lung cancer death rates were higher among Japanese never-smokers compared with the Americans; however, there were differences in definition of smoking, which could have resulted in inclusion of more former smokers among the Japanese never-smokers. ${ }^{11}$ These issues are best resolved with prospective studies evaluating incidence rates, which would be a better reflection of risk.

It is likely that never-smokers across the world have similar susceptibility to lung cancer. The subsequent discussion will address (1) whether there is a biological basis for differences between never-smokers and smokers; (2) the possible aetiological factors for the development of lung cancer; and (3) future research directions for this group of patients.

\section{IS LUNG CANCER AMONG NEVER- SMOKERS A DIFFERENT DISEASE} ENTITY FROM THAT IN SMOKERS?

Many epidemiological studies have found that the characteristics of lung cancer among never-smokers are significantly different from those among smokers. ${ }^{1} 812$ Consistent findings include a higher proportion of women, presence of adenocarcinoma, as well as an earlier age at diagnosis among the never-smokers. We recently reported that the never-smokers with lung cancer also have better survival compared with the smokers, after adjusting for sex, performance status, stage, comorbidities, significant weight loss and treatment. ${ }^{8}$ This was also seen in several other studies. ${ }^{13}$ The improved survival suggests that lung cancer in the neversmokers may be biologically different and inherently more indolent. In the molecular analysis of tumours from patients in a trial of erlotinib versus placebo, ${ }^{14}$ there is a suggestion that tumours with EGFR mutations, when untreated, may have a more indolent behaviour. As EGFR mutations are more commonly found in neversmokers, this further supports the hypothesis in question. The converse is also true, as histological subtypes exclusively associated with smoking, such as small-cell lung cancer and the pleomorphic variant of non-small-cell lung cancer, have an extremely aggressive behaviour.

Prior to the reporting of EGFR mutations, other genetic alterations have been described to be different between smokers and never-smokers. These include deletions of the short arm of chromosome $3,{ }^{15}$ mutations of the $\mathrm{p} 53^{16}$ and K-ras genes. ${ }^{17}$ Although Gealy et al ${ }^{18}$ found that the frequency of mutations in the p53 gene was similar in lifetime never-smokers compared with long-term smokers, the types and spectra of mutations were significantly different between the two groups, again suggesting that different pathways may be involved leading to p53 mutation. Gene expression profiles using microarray analysis have been obtained for lung adenocarcinomas of smokers and never-smokers. ${ }^{19}$ Four times as many genes changed in the transition between non-malignant lung and tumour in smokers compared with never-smokers, suggesting that the non-malignant lung of smokers already had many alterations in gene expression. This is consistent with the fact that smoking causes widespread genetic changes in the lungs of smokers. The corollary is that tumours in neversmokers arise within a field of relatively normal cells.

Additional studies ${ }^{20}$ have examined histologically normal bronchial and bronchiolar epithelium from patients with lung adenocarcinoma containing EGFR mutations among never-smokers. In all, $43 \%$ of patients with EGFR mutant adenocarcinoma had mutations in the normal respiratory epithelium, whereas none was found in those without mutations in their tumours. In addition, these mutations were found more frequently in the normal epithelium within tumour than in adjacent sites. This suggests that EGFR mutations, more common among never-smokers, may be important in the pathogenesis of lung cancer. Recent mechanistic studies have shown that transfection of normal type II pneumocytes with mutant EGFR can lead to the development of adenocarcinoma. ${ }^{21}$ Further evidence for independent pathways for lung adenocarcinomas between smokers and never-smokers was also found in the epigenetic alteration of tumour suppressor genes. ${ }^{22}$

As illustrated above, there are possible divergent pathways of lung cancer development between smokers and neversmokers. Preliminary work in our centre, which is prospectively performing gene expression profiling of newly diagnosed 
patients with lung cancer, shows a clear delineation between smokers and nonsmokers that is independent of histology. ${ }^{23}$ Hopefully, we may be able to provide more information about the molecular differences between the two groups of patients and its relation to prognosis, response to current therapeutic modalities, and development of therapeutics directed along a new pathway.

\section{POSSIBLE AETIOLOGICAL FACTORS FOR LUNG CANCER IN NEVER- SMOKERS \\ Genetic}

Never-smokers with non-small cell lung cancer have a median age of diagnosis of lung cancer that is 7 years earlier than that of smokers. ${ }^{8}$ Koo and $\mathrm{Ho}^{1}$ also described that, among Asians, younger patients with lung cancer tend to be never-smokers. Most early-onset cancers have some genetic predisposition, and a genetic component be involved in the carcinogenesis of lung cancer. Due to a similar shared environment, whether the aggregation of cancer within a family is the result of exposure to tobacco smoke in the same household or is truly a higher predisposition of the individuals may be difficult to determine. Despite this, a series of studies has shown an increased susceptibility among the relatives of patients with lung cancer, after adjusting for smoking exposure. Tokuhata and Lilienfeld ${ }^{24}$ first reported an increase in lung cancer mortality in relatives of lung cancer probands, especially among female never-smoking relatives. Further studies, including case-control ${ }^{25} 26$ and registrybased investigations, ${ }^{27}{ }^{28}$ have shown about a twofold increase in risk of lung cancer among relatives of patients after adjusting for smoking and age. Among these studies, some have found that the familial risk was higher among relatives of never-smoking lung cancer probands, whereas others have reported that the increased risk was limited to early-onset cases. Schwartz et al ${ }^{26}$ reported a sixfold increase in lung cancer among family members of never-smokers with lung cancer, but this was limited to probands $<60$ years of age. Kreuzer et $a l^{29}$ found that lung cancer in a first-degree relative was associated with a 2.6-fold increase in risk of lung cancer in younger people $(\leqslant 45$ years old) compared with older people (55-69 years old), while Bromen et $a l^{30}$ reported a 4.75 -fold increase in lung cancer risk among young subjects $(\leqslant 50$ years old $)$. These studies are limited by small numbers of patients with early-onset disease and varying definitions of young, which is often arbitrarily defined. Despite these limitations, most of these epidemiological studies suggest a trend of a mild to moderate increase in risk of lung cancer among relatives of patients with lung cancer, especially among those with early onset of disease.

This increase in risk of cancers among the relatives of probands does not seem to be limited to lung cancer as Schwartz et $a l^{31}$ reported in another study that family members of never-smoking patients with lung cancer had increased risk for cancers other than lung cancer. Gorlova et $a l^{32}$ also found that a history of early-onset $(<50$ years old) cancer (including breast lung, skin and colon cancer) among firstdegree relatives was associated with significantly increased risk in lung cancer in their study subjects.

Although most studies have described positive associations, there are also studies showing negative associations. Etzel et $a l^{33}$ evaluated the risk for smokingrelated cancers (defined as lung, bladder, head and neck, kidney and pancreatic cancers) among relatives of patients with lung cancer. They did not find evidence of familial aggregation of smoking-related cancers among young people with lung cancer $(\leqslant 55$ years old). They also found no increased risk of lung cancer among relatives of never-smoking people. However, the number of never-smoking patients in their study was quite small $(<10 \%)$.

Interethnic differences in the incidence of lung cancer attest further to a possible genetic component in the risk of lung cancer. A large US study on early-onset lung cancer (in patients $<50$ years old) found that the first-degree relatives of African American individuals have greater risk of lung cancer than Caucasian Americans. ${ }^{34}$ Other supporting evidence for a genetic link in lung cancer carcinogenesis includes the recent finding of a major susceptibility locus that can influence lung cancer risk at the short arm of chromosome $6 .^{35}$

The genetic inheritance of lung cancer possibly involves low-penetrance oncogenes or tumour suppressor genes. In addition, genetic differences in cancer susceptibility that may involve metabolism of carcinogens, DNA repair, apoptosis, angiogenesis and other hallmarks of cancer remain to be elucidated.

\section{Environment}

Passive smoking is a known cause of lung cancer among never-smokers. More than 50 studies have found an association between passive smoking and lung cancer. $^{36}$ The pooled excess risk of lung cancer from exposure to spousal smoking was about $20 \%$ for women and $30 \%$ for men, whereas exposure to environmental tobacco smoke at the workplace increases the risk to about 12-19\%. However, passive smoking cannot explain all the lung cancer cases among never-smokers, as only an estimated 3000 deaths due to lung cancer in the US were attributable to second-hand smoke, ${ }^{37}$ which leaves the majority of cases unaccounted for. Furthermore, molecular differences in tumours between smokers and neversmokers suggest that the causative factor(s) is unlikely to be tobacco smoke, as the same aetiological agent should usually result in similar genomic profiles.

Other well-described causes include indoor exposure to asbestos, radon, arsenic, chromium, nickel, tar and soot. However, only a few have been studied specifically in never-smokers. A review of literature on occupational lung cancer in never-smokers found that asbestos, radon decay products and possibly arsenic are occupational carcinogens. ${ }^{38}$ Abbey et al, ${ }^{39}$ in a study on never-smoking individuals, found that inhalable particles $<10 \mu \mathrm{m}$ in diameter showed a strong association with lung cancer deaths for males, while Gorlova et $a l^{32}$ showed that exposure to dust in never-smokers was associated with an increased risk of lung cancer. There are many other causes that have been postulated and suggested by studies, but results of many are not duplicated, so the purported causative factors remain as postulations.

Many risk-evaluation studies focusing on never-smoking individuals have been performed in Asia. Several interesting postulations are discussed here. In Taiwan, investigators found a high prevalence of human papillomavirus (HPV) 16/18 among never-smoking female lung cancer patients compared with the males and suggested an association between HPV and lung cancer. ${ }^{40}$ They further tested blood HPV DNA and found that the prevalence rate of HPV 16/18 in lung cancer cases was significantly higher than that among controls without cancer. ${ }^{41}$ However, Shigematsu et $a l^{42}$ did not find any relationship between the presence of high-risk HPV DNA sequences (HPV 16 and 18) and EGFR TK domain mutations in their tumour specimens from Taiwan.

A case-control study in Taiwan found a higher risk of lung cancer among women who waited until the cooking oil has been heated and did not use a fume extractor, suggesting that a proportion of lung cancer cases may be attributable to cooking oil fumes. ${ }^{43}$ However, this was not duplicated in a study among Singapore Chinese women, ${ }^{44}$ which could be related to different cooking practices. Other case-control studies have found that diet can affect the risk of lung cancer, including a protective effect from tomatoes and lettuce, and a detrimental effect from meat consumption. ${ }^{45}$ Dietary 
phyto-oestrogens have also been shown to be associated with a reduction in the risk of lung cancer. ${ }^{46}$ Further analysis of a European study found that the combination of two common risk factors, low dietary consumption of lettuce and high exposure to environmental tobacco smoke, can increase the odds ratio of lung cancer among never-smokers by twofold. ${ }^{47}$

How do we interpret the abundance of studies, mainly case-control designs, which suggest the protective or detrimental effect of a particular environmental or genetic factor? The important thing to bear in mind is that the factors studied do not occur in isolation. Every individual is genetically heterogeneous and exposed to multiple factors within the environment. No doubt the environment plays a dominant role in most common cancers, ${ }^{48}$ but the contribution of genetic factors cannot be simply dismissed. The myriad of ongoing gene-association studies attests to the importance of studying geneenvironment interactions in lung cancer causation, and never-smokers represent the ideal subjects to examine unknown, yet important, environmental and genetic factors.

\section{FUTURE DIRECTIONS}

It is imperative that investigators adopt a consistent definition of a never-smoker in order to allow comparisons across all studies. Most studies define a neversmoker as one who either has never smoked at all or has smoked $<100$ cigarettes (or the equivalent amount of tobacco) in his or her lifetime, which is in line with that proposed by the World Health Organization. ${ }^{49}$

It has been consistently observed that most never-smokers are women, and that most women with lung cancer are neversmokers. Due to this intricate relationship between non-smoking status and women, it is important to unravel the associations between lung cancer, smoking status and sex. Whether never-smoking women are at an increased risk of lung cancer compared with men is still controversial, although Thun et $a l^{9}$ found that the lung cancer death rates are higher in men than in women. Preliminary analysis of our cohort of patients with lung cancer seems to show that there are no differences between never-smoking men and women.

Another priority area would be geneenvironment association studies that are needed to unravel important aetiological factors in the causation of lung cancer among the never-smokers. Due to the complexity of the interaction, these studies have to be of optimal design, quality and size in order to have clinically relevant outcomes. This will require international collaboration as well as close cooperation between clinicians, scientists and epidemiologists to achieve the goal in a realistic time. Detailed studies into the family history, environmental factors and polymorphisms in genes related to DNA repair and carcinogen metabolism would be of importance.

\section{CONCLUSION}

Understanding the biology of lung cancer in never-smokers will be important in the present era of targeted therapy and personalised medicine. Developing a robust genotype-phenotype correlation and selecting the right population ${ }^{50}$ is going to be increasingly important. The days of non-selective killing of cancer cells with chemotherapeutic agents are numbered, as drugs that target a selected group of patients are now being developed. Never-smokers with lung cancer represent a select group of patients who may possibly be treated differently from smokers in the foreseeable future. The ongoing large randomised phase III study in Asia $^{51}$ focusing on never-smokers and light smokers is an example of studies that should continue to take place in the future. Henceforth, never-smokers with lung cancer should no longer feel ignored.

\section{ACKNOWLEDGEMENTS}

This work is supported in part by National Medical Research Council grants NMRC/0939/ 2005 and NMRC/0941/2005.

J Clin Pathol 2007;60:337-340.

doi: $10.1136 /$ icp.2006.040576

\section{Authors' affiliations}

Chee-Keong Toh, Wan-Teck Lim, Department of Medical Oncology, National Cancer Centre, Singapore

Correspondence to: Dr C-K Toh, Department of Medical Oncology, National Cancer Centre, Singapore 169610, Singapore; dmotck@nccs. com.sg

\section{Accepted 27 July 2006}

\section{Published Online First 17 August 2006}

Competing interests: None declared.

\section{REFERENCES}

1 Koo LC, Ho JH. Worldwide epidemiological patterns of lung cancer in nonsmokers. Int J Epidemiol 1990; 19(Suppl 1):S14-23.

2 Gao YT, Blot WJ, Zheng W, et al. Lung cancer among Chinese women. Int J Cancer 1987;40:604-9

3 Pao W, Miller V, Zakowski M, et al. EGF receptor gene mutations are common in lung cancers from "never smokers" and are associated with sensitivity of tumors to gefitinib and erlotinib. Proc Natl Acad Sci USA 2004;101:13306-11

4 Lynch TJ, Bell DW, Sordella R, et al. Activating mutations in the epidermal growth factor receptor underlying responsiveness of non-small-cell lung cancer to gefitinib. $\mathrm{N}$ Engl $\rfloor$ Med

2004;350:2129-39.

5 Paez JG, Janne PA, Lee JC, et al. EGFR mutations in lung cancer: correlation with clinical response to gefitinib therapy. Science 2004;304:1497-500.

6 Epidemiology \& Disease Control Division, Ministry of Health, Singapore. National health surveillance survey. 2001:15-23.

7 Parkin DM, Pisani $P$, Lopez $A D$, et al. At least one in seven cases of cancer is caused by smoking: global estimates for 1985. Int J Cancer 1994;59:494-504.

8 Toh CK, Gao F, Lim WT, et al. Never-smokers with lung cancer: epidemiological evidence of a distinct disease entity. J Clin Oncol 2006;24:2245-51.

9 Thun MJ, Henley SJ, Burns D, et al. Lung cancer death rates in lifelong nonsmokers. J Natl Cancer Inst 2006;98:691-9.

10 Chia KS, Seow A, Lee HP, et al. Cancer incidence in Singapore 1968-2002. Singapore Cancer Registry Report No. 6 2004:8.

11 Marugame T, Sobue T, Satoh $\mathrm{H}$, et al. Lung cance death rates by smoking status: comparison of the three-prefecture cohort study in Japan to the cancer prevention study II in the USA. Cancer Sci 2003;96:120-6.

12 Koo LC, Ho JH, Lee N. An analysis of some risk factors for lung cancer in Hong Kong. Int $J$ Cancer 1985:35: 149-55.

13 Nordquist LT, Simon GR, Cantor A, et al. Improved survival in never-smokers vs current smokers with primary adenocarcinoma of the lung. Chest 2004; 126:347-51.

14 Tsao MS, Sakurada A, Cutz JC, et al. Erlotinib in lung cancer-molecular and clinical predictors of outcome. N Engl J Med 2005;353:133-44.

15 Mitsudomi T, Oyama T, Nishida K, et al. Loss of heterozygosity at $3 p$ in non-small cell lung cancer and its prognostic implication. Clin Cancer Res 1996;2:1185-9.

16 Suzuki H, Takahashi T, Kuroishi T, et al. p53 mutations in non-small cell lung cancer in Japan: association between mutations and smoking. Cancer Res 1992;52:734-6.

17 Ahrendt SA, Decker PA, Alawi EA, et al. Cigarette smoking is strongly associated with mutation of the $\mathrm{K}$ ras gene in patients with primary adenocarcinoma of the lung. Cancer 2001;92:1525-30.

18 Gealy R, Zhang L, Siegfried JM, et al. Comparison of mutations in the p53 and K-ras genes in lung carcinomas from smoking and nonsmoking women. Cancer Epidemiol Biomarkers Prev 1999;8:297-302.

19 Powell CA, Spira A, Derti A, et al. Gene expression in lung adenocarcinomas of smokers and nonsmokers. Am J Respir Cell Mol Biol 2003;29:157-62

20 Tang $X$, Shigematsu $H$, Bekele BN, et al. EGFR tyrosine kinase domain mutations are detected in histologically normal respiratory epithelium in lung cancer patients. Cancer Res 2005:65:7568-72.

$21 \mathrm{Ji} \mathrm{H}$, Li D, Chen L, et al. The impact of human EGFR kinase domain mutations on lung tumorigenesis and in vivo sensitivity to EGFR-targeted therapies. Cancer Cell 2006;9:485-95.

22 Toyooka S, Tokumo M, Shigematsu $\mathrm{H}$, et al. Mutational and epigenetic evidence for independent pathways for lung adenocarcinoma arising in smokers and never smokers. Cancer Res 2006:66:1371-5.

23 Tan EH, Hsu A, Eng P, et al. Molecular profiling of lung cancer: can it be used as a clinical too [abstract]? Lung cancer 2005;49(Suppl 2):S147.

24 Tokuhata GK, Lilienfeld AM. Familial aggregation of lung cancer in humans. J Natl Cancer Inst 1963;30:289-312.

25 Ooi WL, Elston RC, Chen VW, et al. Increased familial risk for lung cancer. J Natl Cancer Inst 1986;76:217-22

26 Schwartz AG, Yang P, Swanson GM. Familial risk of lung cancer among nonsmokers and their relatives. Am J Epidemiol 1996;144:554-62.

27 Jonsson S, Thorsteinsdottir U, Gudbjartsson DF, ef al. Familial risk of lung carcinoma in the Icelandic population. JAMA 2004;292:2977-83.

28 Czene K, Lichtenstein P, Hemminki K. Environmental and heritable causes of cancer among 9.6 million individuals in the Swedish family-cancer database. Int J Cancer 2002;99:260-6. 
29 Kreuzer M, Kreienbrock L, Gerken M, et al. Risk factors for lung cancer in young adults. Am J Epidemiol 1998;147:1028-37.

30 Bromen K, Pohlabeln H, Jahn I, et al. Aggregation of lung cancer in families: results from a populationbased case-control study in Germany. Am J Epidemiol 2000;152:497-505.

31 Schwartz AG, Rothrock M, Yang P. Increased cancer risk among relatives of nonsmoking lung cancer cases. Genet Epidemiol 1999;17:1-15.

32 Gorlova OY, Zhang Y, Schabath MB, et al. Never smoker and lung cancer risk: a case-control study of epidemiological factors. Int J Cancer 2006; 1 18:1798-804

33 Etzel CJ, Amos Cl, Spitz MR. Risk for smoking related cancer among relatives of lung cancer patients. Cancer Res 2003;63:8531-5.

34 Cote ML, Kardia SLR, Wenzlaff AS, et al. Risk of lung cancer among white and black relatives of individuals with early-onset lung cancer. JAMA 2005;293:3036-42

35 Bailey-Wilson JE, Amos Cl, Pinney SM, et al. A major lung cancer susceptibility locus maps to chromosome 6q23-25. Am J Hum Genet 2004;75:460-74.

36 Vineis $\mathbf{P}$, Alavanja $M$, Buffler $P$, et al. Tobacco and cancer: recent epidemiological evidence. J Natl Cancer Inst, 2004;96, 99-106.
37 Centers for Disease Control, Prevention (CDC). Annual smoking-attributable mortality, years of potential life lost, and productivity losses- United States, 1997-2001. MMWR Morb Mortal Wkly Rep 2005;54:625-8.

38 Neuberger JS, Field RW. Occupation and lung cancer in nonsmokers. Rev Environ Health 2003; 18:251-67.

39 Abbey DE, Nishino N, McDonnell WF, et al. Long term inhalable particles and other air pollutants related to mortality in nonsmokers. Am J Respir Crit Care Med 1999;159:373-82.

40 Cheng YW, Chiou HL, Shue GT, et al. The association of human papillomavirus 16/18 infection with lung cancer among nonsmoking Taiwanese women. Cancer Res 2001;61:2799-803.

41 Chiou HL, Wu MF, Liaw YC, et al. The presence of human papillomavirus type 16/18 DNA in blood circulation may act as a risk marker of lung cancer in Taiwan. Cancer 2003;97:1558-63.

42 Shigematsu H, Lin L, Takahashi T, et al. Clinical and biological features associated with epidermal growth factor receptor gene mutations in lung cancers. J Natl Cancer Inst 2005;97:339-46.

43 Ko YC, Cheng LS, Lee CH, et al. Chinese food cooking and lung cancer in women nonsmokers. Am J Epidemiol 2000;151:140-7.
44 Seow A, Poh WT, Teh $M$, et al. Fumes from meat cooking and lung cancer risk in Chinese women. Cancer Epidemiol Biomarkers Prev 2000;9:1215-21

45 Brennan $\mathbf{P}$, Fortes $\mathrm{C}$, Butler J, et al. A multicenter case-control study of diet and lung cancer among non-smokers. Cancer Causes Control 2000;11:49-58.

46 Schabath MB, Hernanadez LM, Wu X, et al. Dietary phytoestrogens and lung cancer risk. JAMA 2005;294: 1493-504

47 Brennan P, Butler J, Agudo A, et al. Joint effect of diet and environmental tobacco smoke on risk of lung cancer among nonsmokers. J Natl Cancer Institute 2000;92:426-7.

48 Hoover RN. Cancer-nature, nurture, or both N Engl J Med 2000;343:135-6.

49 World Health Organization. Guidelines for controlling and monitoring the tobacco epidemic. Geneva, Switzerland: World Health Organization, 1998.

50 Lim WT, McLeod HL. Individualizing cancer therapy. In: Young A, Rowett L, Kerr D, eds. Cancer biotherapy; an introductory guide. Oxford: Oxford University Press, 2006

51 AstraZeneca. Ph III 1 st line IRESSA versus Carbo/ Paclitaxel in Asia (IPASS). http:// www.clinicaltrials.gov/ct/show/NCT00322452 (accessed 8 Feb 2007). 